\title{
Growth of micrometric oxide layers to explore laser decontamination of metallic surfaces
}

\author{
Luisa Carvalho*, Wilfried Pacquentin, Michel Tabarant, Hicham Maskrot, and Alexandre Semerok \\ Den - Service d'Etudes Analytiques et de Réactivité des Surfaces (SEARS), CEA, Université Paris-Saclay, \\ 91191 Gif sur Yvette, France
}

Received: 10 July 2017 / Received in final form: 9 October 2017 / Accepted: 10 October 2017

\begin{abstract}
The nuclear industry produces a wide range of radioactive waste in terms of hazard level, contaminants and material. For metallic equipment like steam generators, the radioactivity is mainly located in the oxide surface. In order to study and develop safe techniques for dismantling and for decontamination, it is important to have access to oxide layers with a representative distribution of non-radioactive contaminants. In this paper we propose a method for the creation of oxide layers on stainless steel 304L with europium (Eu) as contaminant. This technique consists in spraying an Eu-solution on stainless steel samples. The specimens are firstly treated with a pulsed nanosecond laser after which the steel samples are placed in a $873 \mathrm{~K}$ furnace for various durations in order to grow an oxide layer. The oxide structure and in-depth distribution of Eu in the oxide layer were analyzed by scanning electron microscopy coupled to an energy-dispersive X-ray microanalyzer, as well as by glow discharge optical emission or mass spectrometry. The oxide layers were grown to thicknesses in the range of $200 \mathrm{~nm}-4.5 \mu \mathrm{m}$ depending on the laser treatment parameters and the heating duration. These contaminated oxides had a 'duplex structure' with a mean concentration of the order of $6 \times 10^{16}$ atoms/ $\mathrm{cm}^{2}\left(15 \mu \mathrm{g} / \mathrm{cm}^{2}\right)$ of europium in the volume of the oxide layer. It appears that europium implementation prevented the oxide growth in the furnace. Nevertheless, the presence of the contamination had no impact on the thickness of the oxide layers obtained by preliminary laser treatment. These oxide layers were used to study the decontamination of metallic surfaces such as stainless steel 304L using a nanosecond pulsed laser.
\end{abstract}

\section{Introduction}

In the nuclear industry, dismantling is a major issue. The contaminated surfaces vary widely in terms of characteristics such as shape (pipes, plane surfaces, etc.), conditions of oxide growth (temperature, atmosphere, etc.) and nature of contaminants. In regard to metallic components such as pipe systems, radio nuclides are typically found in the oxide layer, which grows during the operations of the nuclear facility. The cleaning of contaminated surfaces is currently based on chemical and mechanical processes. However, a few problems remain unsolved. These techniques usually generate secondary wastes, contaminated effluents requiring long-term storage and dismantling by workers who thus become exposed to occasional radiation.

In this context, studies have been carried out on the cleaning of contaminated surfaces such as painted concrete $[1,2]$ and stainless steel $[3,4]$ by excimer or fiber lasers. In particular, the CEA (French Alternative Energies and Atomic Energy Commission) has developed a prototype for the cleaning of painted surfaces called Aspilaser [2]. The

\footnotetext{
* e-mail: luisa.carvalho@cea.fr
}

principle of this technique is laser ablation of the surface in order to remove the oxide layer and collect the radioactive particles with a High Efficiency Particulate Air (HEPA) filter for storage. In nuclear facilities, the use of a laser for the cleaning of contaminated surfaces has many advantages such as the possibility of remote treatment without worker exposition. As a dry process, the secondary wastes generated by laser cleaning are the ablated particles and the HEPA filter, that can be stored in a small volume without risk of dispersion.

A previous study [3,5] has highlighted the need to create oxide layers in a controlled manner for the study of the efficiency of laser decontamination and to optimize the cleaning process. The aim of growing oxide layers on metallic surfaces with a non-radioactive contaminant is to study and develop decommissioning techniques without the problems of availability of radioactive samples and the constraints of working in hot laboratories.

The goal of our work has been to find a way of creation of oxide layers with desired characteristics (thickness, Euconcentration) in order to explore laser cleaning. This paper presents the results of growing a micrometric oxide layer contaminated with a non-radioactive element and the preliminary test of laser cleaning. 


\section{Oxidation of stainless steel $304 \mathrm{~L}$ with a non-radioactive marker}

We have investigated a method to form a reproducible micrometric oxide layer on stainless steel AISI 304L (304L SS) with a volume-related distribution of europium (Eu) in the layer thickness. This distribution was chosen in order to consider $\mathrm{Eu}$ as a simulation of a radioactive element (actinide). Thus, the efficiency of decontamination can be determined by measuring the Eu concentration before and after laser decontamination. The initial composition of the 304L SS samples was analyzed via glow discharge mass spectrometry (GDMS) and no trace of Eu was found with a detection limit of $0.1 \mathrm{mg} / \mathrm{kg}(0.1 \mathrm{ppm})$ of metal.

\subsection{Procedure}

Specimens $(30 \mathrm{~mm} \times 30 \mathrm{~mm} \times 3 \mathrm{~mm})$ were cut by a water jet from a cold-rolled 304L stainless steel sheet. The coupons were cleaned in an ultrasound bath with ethanol. The average surface roughness has been measured by optical profiler and estimated to be $R a=0.46 \pm 0.13 \mu \mathrm{m}$. The contamination was generated before oxidation by deposition of a solution of $\mathrm{Eu}\left(\mathrm{NO}_{3}\right)_{3}$ in water at an Euconcentration of $4000 \mathrm{mg} / \mathrm{L}$. The solution was sprayed with a nebulizer and the flow was controlled by a pumping device. The samples were heated using a hot plate at $473 \mathrm{~K}$ until the deposition had dried. It was estimate that the deposited amount of $\mathrm{Eu}$ was 0.5 up to $1.0 \mathrm{mg} / \mathrm{cm}^{2}(1.6-$ $3.2 \times 10^{19}$ atoms $\left./ \mathrm{cm}^{2}\right)$. Certain samples without contamination served as control samples.

Pre-oxidation was carried out by laser treatment in air at atmospheric pressure. The setup comprised an ytterbium fiber laser (Gaussian beam, $M^{2}=2.1, \lambda=1064 \mathrm{~nm}$, mean power up to $20 \mathrm{~W}$, repetition rate $v=20 \mathrm{kHz}$, pulse duration $\tau=110 \mathrm{~ns}$ at FWHM), a scanning system, a focusing lens $(f=420 \mathrm{~mm})$ resulting in a laser beam waist radius $\omega=84 \pm 2 \mu \mathrm{m}$ (at $1 / \mathrm{e}^{2}$ intensity level) and an air aspiration system. For the oxidation regime, the samples were mounted on a micro control assembly and placed at the focal lens. The power of the beam varied between 5 and $18 \mathrm{~W}$ in order to study a maximal fluence per pulse $(F)$ in the range $2.2-7.8 \mathrm{~J} / \mathrm{cm}^{2}$ (maximal fluence on the beam axis).

The laser treatment was conducted by horizontal and vertical scanning (Fig. 1). The horizontal scanning was characterized by the scanning speed $V$ in order to define the step $\Delta x$ between two consequent laser spots. The vertical scanning was defined by the vertical step $\Delta y$ between two parallel lines.

The scan speed and the distance between lines were chosen to provide a high spatial overlapping between two successive spots from $80-95 \%$. The overlapping percentage was calculated using the laser spot beam diameter at $1 / \mathrm{e}^{2}$. The laser treatment was defined by the maximum beam fluence $F$ per pulse and the delivered energy amount $E$ per surface unit of the sample after the treatment. $F$ is calculated as follows:

$$
F=E_{\text {pulse }} / S=2 P / v \pi \omega^{2},
$$

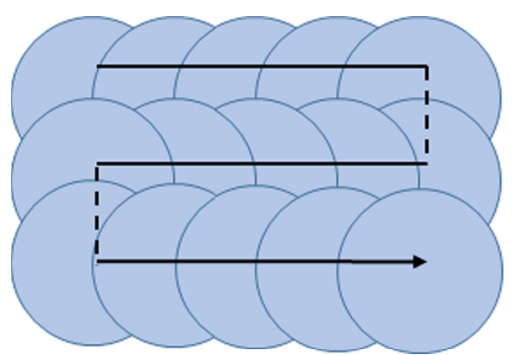

Fig. 1. Pattern of the scanning regime. The circles represent the consecutive laser spots on the treated surface and the continuous arrow shows the laser beam path.

where $E_{\text {pulse }}$ is the energy per pulse in joule and $S$ is the surface of the laser spot in $\mathrm{cm}^{2}$. The energy per pulse is the laser average power $(P)$ divided by the repetition rate $v$ of $20 \mathrm{kHz}$. The average energy per surface unit delivered by the laser source on the sample $E$ is determined as follows:

$$
E=P \Delta t / S_{s},
$$

where $\Delta t$ is the treatment duration and $S_{s}$ is the total treated surface in $\mathrm{cm}^{2}$. A part of the energy delivered by the laser source is lost by reflection on the surface. The absorption coefficient of the AISI 304L samples at $\lambda=1064 \mathrm{~nm}$ was determined by integrating sphere and is estimated to be $29 \pm 2 \%$. In this work, we study oxide layers formed by a delivered energy $E$ in a range from 50 to $600 \mathrm{~J} / \mathrm{cm}^{2}$.

After laser treatment, the oxidized samples were placed in a furnace at $873 \mathrm{~K}$ for 50 or 100 hours in air at atmospheric pressure and their cooling was done in the furnace after it was switched off. Such a furnace treatment makes it possible to grow the oxide layer to a thickness up to $4.5 \mu \mathrm{m}$ depending on the oxidation time in the furnace.

\subsection{Characterization of the oxide coatings}

The oxidation procedure resulted in the creation of Eucontaminated oxide layers with a thickness from $200 \mathrm{~nm}$ to $4.5 \mu \mathrm{m}$ depending on the set of laser parameters and the duration of the heating. The obtained oxide layers were characterized and analyzed by glow discharge optical emission spectrometry (GD-OES), GDMS, scanning electron microscopy (SEM) coupled with an energy dispersive X-ray analyzer (EDX), X-ray diffraction (XRD) and micro-Raman spectroscopy.

The Eu-contaminated layer formed after the pre oxidation by laser was analyzed by GD-OES and the indepth distribution of the elements is presented in Figure 2. One can see that the laser treatment resulted in the creation of an oxide layer (mostly Fe- and Cr-oxide) of a thickness of $500 \mathrm{~nm}$ with an Eu distribution in the whole oxide thickness and with a mean Eu-concentration up to $3.8 \mathrm{wt} . \%$ or $6 \times 10^{16}$ atoms $/ \mathrm{cm}^{2}$.

A GD-OES profile and a SEM image (back scattering electrons $)$ of a representative oxide layer $\left(E=600 \mathrm{~J} / \mathrm{cm}^{2}\right.$, oxidation time in the furnace of $50 \mathrm{~h}$ ) are shown in Figures 3 and 4 . 


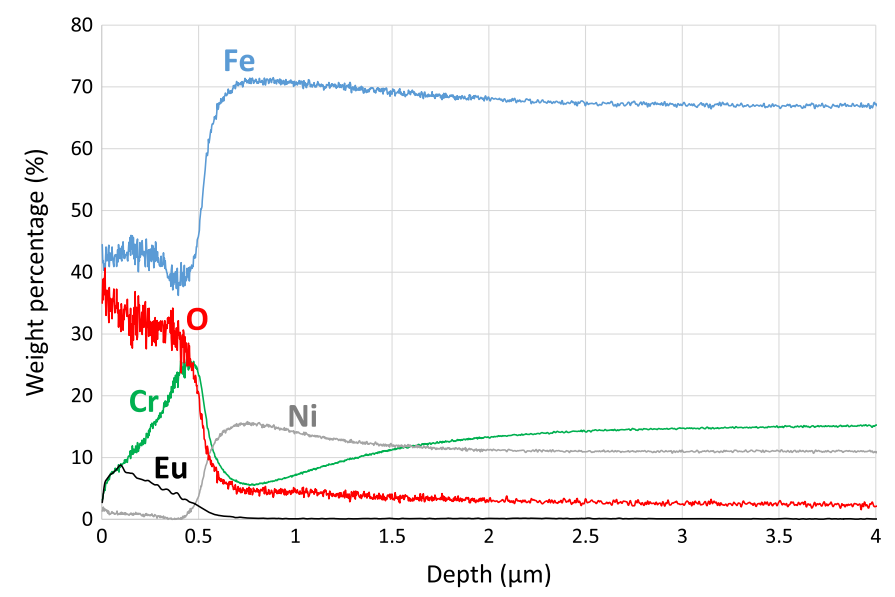

Fig. 2. GD-OES profile of an Eu-contaminated oxide layer on $304 \mathrm{~L}$ SS after a preliminary laser treatment $(9 \mathrm{~W}$, overlapping of $95 \%, E=600 \mathrm{~J} / \mathrm{cm}^{2}$ ) and without furnace treatment. The oxide thickness was estimated to be $500 \mathrm{~nm}$.

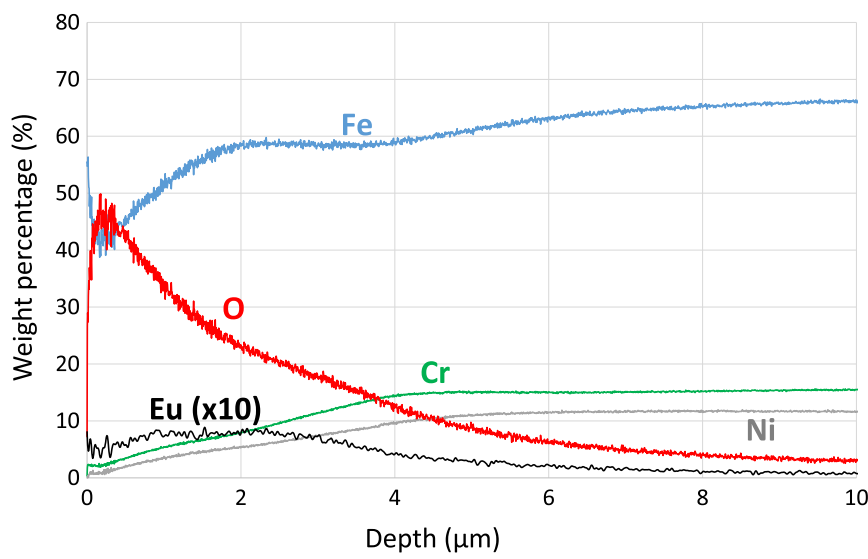

Fig. 3. GD-OES profile of an Eu-contaminated oxide layer on 304L SS after preliminary laser treatment (9 W, overlapping of $\left.95 \%, E=600 \mathrm{~J} / \mathrm{cm}^{2}\right)$ and oxidation in the furnace $(50 \mathrm{~h}, 873 \mathrm{~K})$. The oxide thickness was estimated to be $4.5 \mu \mathrm{m}$. The scale of Eudistribution was multiplied by 10 in order to be readable.

The oxidation in the furnace led to a layer of $4.1 \pm 1.4 \mu \mathrm{m}$ with a contamination of $0.40 \pm 0.13 \mathrm{wt} . \%$ of $\mathrm{Eu}$ in the whole thickness. The thermal treatment only induced diffusion of contaminant, thus the concentration remains at $6 \times 10^{10}$ atoms $/ \mathrm{cm}^{2}$. In both Figures 2 and 3 , the distribution of $\mathrm{Eu}$ followed the oxygen distribution, signifying that the contamination was strictly retained in the oxide layer, and not detected in the bulk of the metal. The low detection limit of GD-OES $(100 \mu \mathrm{g} / \mathrm{g}$ for Eu) allow us to highlighted the presence of $\mathrm{Eu}$ in the whole oxide.

Complementary investigation has been achieved by SEM coupled with EDX (Fig. 4). This technique allowed us to have access to the oxide thickness and to its chemical composition. However, in the conditions of observation (acceleration tension of $15 \mathrm{keV}$ and a current of $2 \mathrm{nA}$ ), the EDX analysis is made on a volume of $1 \mu \mathrm{m}^{3}$ and with a detection limit for $\mathrm{Eu}$ of $1 \%$ in weight, above the mean concentration of Eu in the oxide. For those reasons, mostly

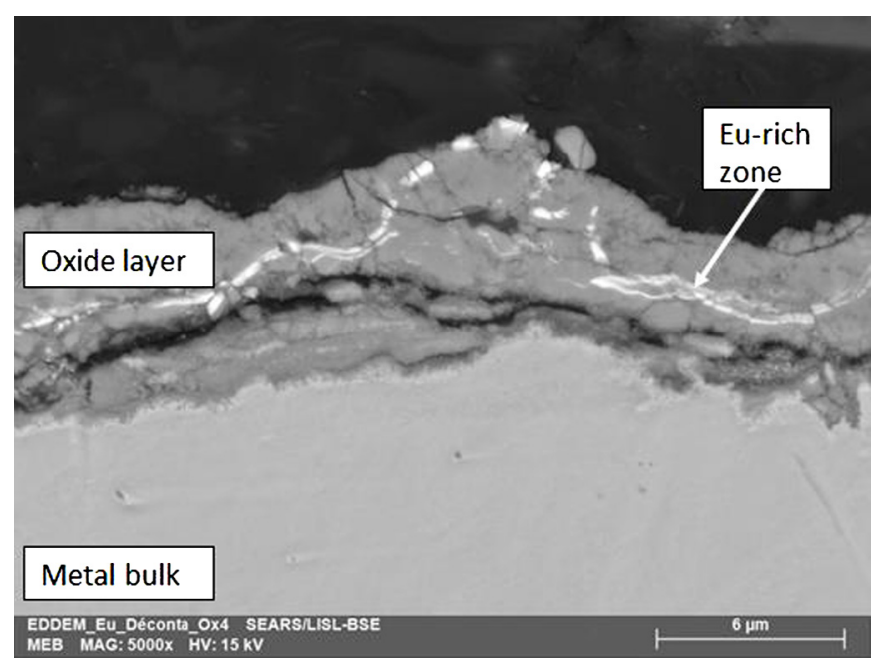

Fig. 4. SEM image (5 000x) of a cross section of a $4.5 \mu \mathrm{m}$ thick Eu-contaminated oxide layer on 304L SS after a preliminary laser treatment (9W, overlapping of $\left.95 \%, E=600 \mathrm{~J} / \mathrm{cm}^{2}\right)$ and oxidation in the furnace $(50 \mathrm{~h}, 873 \mathrm{~K})$.

ferrous oxide was detected and the white parts in the SEM image of the cross section (Fig. 4) only matched the Eu-rich zones (10\% of weight). The resulting contamination level for Eu appeared to be also lower than the detection limit of EDX, XRD and micro-Raman methods. The monitoring of Eu was decided to be conducted by GD-OES and GDMS, which have detection limits of $100 \mu \mathrm{g} / \mathrm{g}$ and $0.1 \mu \mathrm{g} / \mathrm{g}$ for Eu, respectively.

For thick oxide layers, the GD-OES profiles (Fig. 3) and SEM image (Fig. 5) led to the assumption of the presence of a thicker outer layer mainly composed of Fe-rich oxide and an inner one enriched in Cr. The micro-Raman spectroscopy (laser wavelength $\lambda=532 \mathrm{~nm}$ ) and XRD analysis (grazing incidence, $\theta=1^{\circ}$ ) of this sample showed mainly the creation of hematite $\mathrm{Fe}_{2} \mathrm{O}_{3}$ and a mixed oxide of $\mathrm{Fe}$ and $\mathrm{Cr}\left(\mathrm{Fe}_{3} \mathrm{O}_{4} / \mathrm{FeCr}_{2} \mathrm{O}_{4}\right)$. This structure appeared to be similar to the oxide layers in industrial nuclear conditions [6]. The oxide phases identified by XRD in samples with and without $\mathrm{Eu}$ were the same. Moreover, XRD analysis was not able to identify any specific phases with Eu like Eu-rich oxide because the concentration in $\mathrm{Eu}$ was below the detection limit of this technique.

Our result differed from the one in [7], where the authors proceeded with furnace oxidation of 304L SS specimens contaminated with ytterbium. In the study of Riffard et al., the contaminated layer was thinner and the oxide was composed mainly of a Cr-oxide: $\mathrm{Cr}_{2} \mathrm{O}_{3}$. However, our experiments showed the influence of rare earth metals as inhibitors of oxidation in the furnace, which was in accordance with other studies [7-9]. Thanks to our procedure, this blocking behavior of $\mathrm{Eu}$ is avoided by a previous laser scanning. The formation of a first oxide layer with $\mathrm{Eu}$ allows the oxide growth in the furnace.

Our investigations with the objective to find the oxidation condition to control the thickness of the oxide layer led us to test different laser regimes and furnace oxidation durations. 


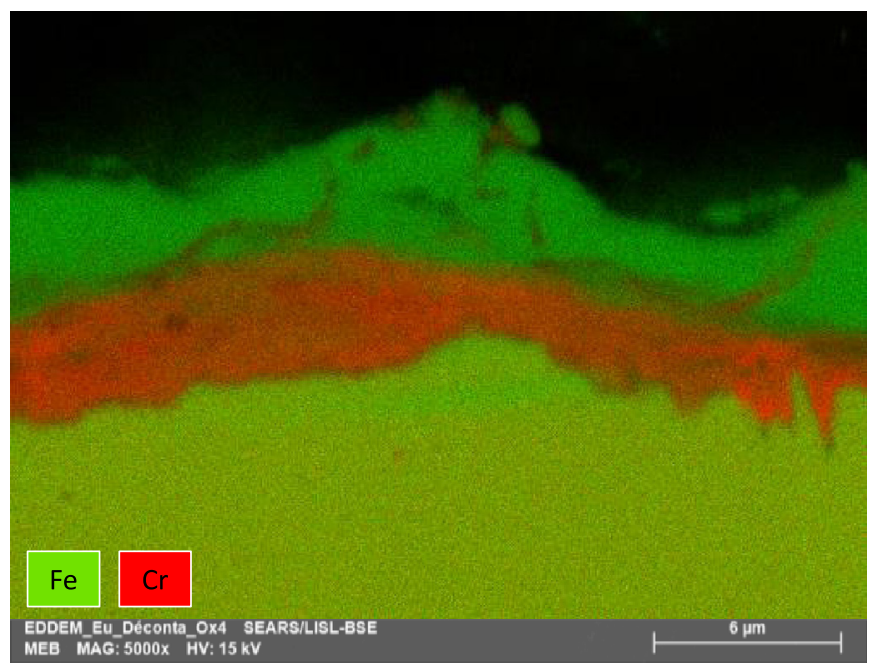

Fig. 5. EDX map of a cross section of a $4.5 \mu \mathrm{m}$ thick Eucontaminated oxide on 304L SS after a preliminary laser treatment $\left(9 \mathrm{~W}\right.$, overlapping of $\left.95 \%, E=600 \mathrm{~J} / \mathrm{cm}^{2}\right)$ and oxidation in the furnace $(50 \mathrm{~h}, 873 \mathrm{~K})$.

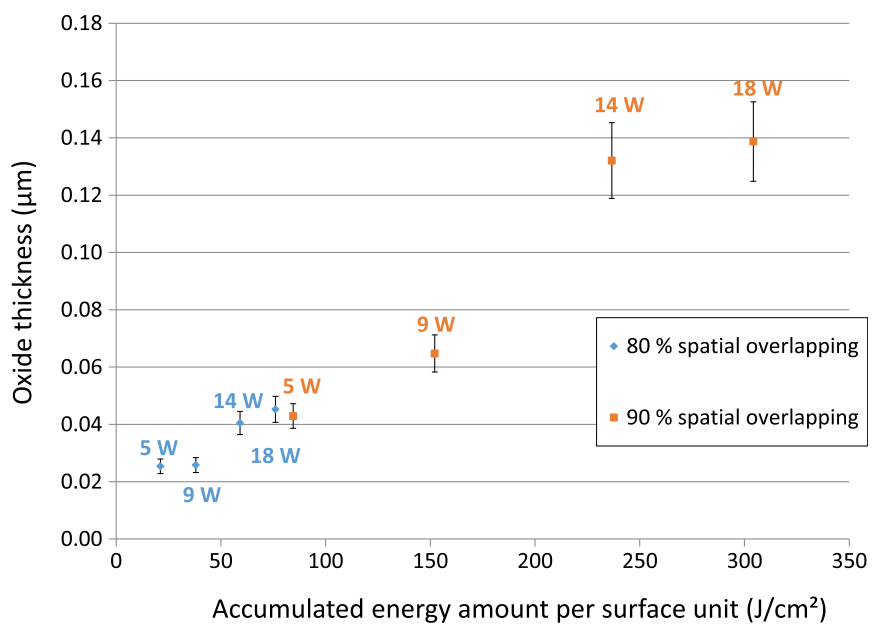

Fig. 6. Oxide thicknesses resulting from different laser irradiations at 5, 9, 14 and $18 \mathrm{~W}$ and $80 \%$ overlap (in blue) or $90 \%$ overlap (in orange).

\subsection{Effect of oxidation parameters}

The first step of our study was to determine the influence of the laser parameters on the preliminary oxide layer. To do so, we varied the delivered energy amount of the laser on the sample surface from 50 to $300 \mathrm{~J} / \mathrm{cm}^{2}$ by using several laser powers $(5,9,14$ and $18 \mathrm{~W})$ and 80 or $90 \%$ of spatial overlap. It was noticed that the preliminary oxide thicknesses ranged from 20 to $140 \mathrm{~nm}$ (Fig. 6). The oxide layers seemed to grow in a linear manner with the delivered energy amount.

Moreover, in the case of the treatments at $18 \mathrm{~W} / 80 \%$ overlap and $5 \mathrm{~W} / 90 \%$ overlap $(40 \mathrm{~nm})$, the oxides were quite similar in thickness although the fluence per pulse differed. This result highlights the fact that the principal oxidation parameter was the delivered energy amount $E$ a)

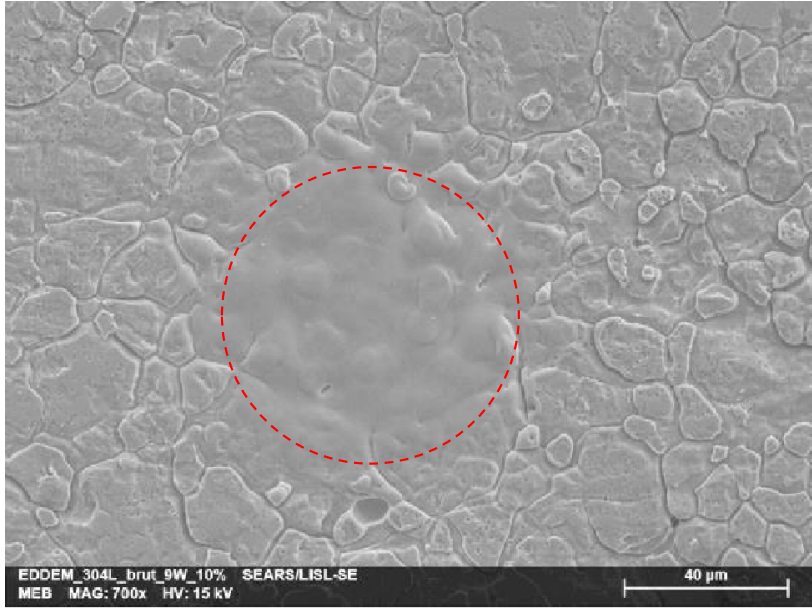

b)

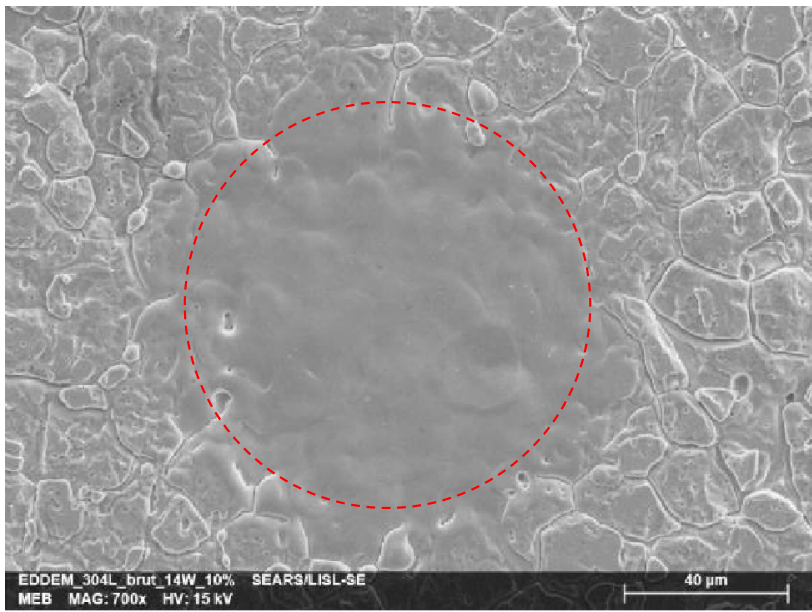

Fig. 7. SEM image ( $\mathrm{x} 700$ ) of a single impact on 304L SS after a different laser treatment: (a) $9 \mathrm{~W}\left(4.1 \mathrm{~J} / \mathrm{cm}^{2}\right)$, (b) $14 \mathrm{~W}$ $\left(6.3 \mathrm{~J} / \mathrm{cm}^{2}\right)$. The red circles represent the thermally affected zone of the sample surface.

and not the fluence per pulse or the spatial overlap. The same experiments were performed without Eu-contamination and it appeared that the presence of $\mathrm{Eu}$ did not interfere with the oxidation by laser.

In order to span a large variety of laser treatments, the laser fluence was varied from 2.2 to $7.8 \mathrm{~J} / \mathrm{cm}^{2}$ per pulse. In the case of a nanosecond pulse, the laser beam energy is absorbed by the surface due to electron excitation and transmitted to the metal lattice by collisions. This implies a localized heating of the metal surface, its oxidation and, possibly, its melting. The creation of the oxide during the laser scanning modifies the physical properties and the interaction regime between the laser and the surface. Interferences between incoming and outgoing beams can occur because of the presence of this semi-transparent oxide and implies temperature oscillations [10]. According to [11], the theoretical laser melt threshold fluence can be estimated by:

$$
\Phi_{m}=(\sqrt{\pi} / 2) \kappa \theta_{m}(\tau / D)^{1 / 2},
$$

where $\kappa=13 \mathrm{~W} / \mathrm{m} \cdot \mathrm{K}$ is the thermal conductivity, $\theta=1678 \mathrm{~K}$ is the melting temperature, $\tau=110 \mathrm{~ns}$ is the laser pulse duration and $D=3.8 \times 10^{-6} \mathrm{~m}^{2} / \mathrm{s}$, the thermal 


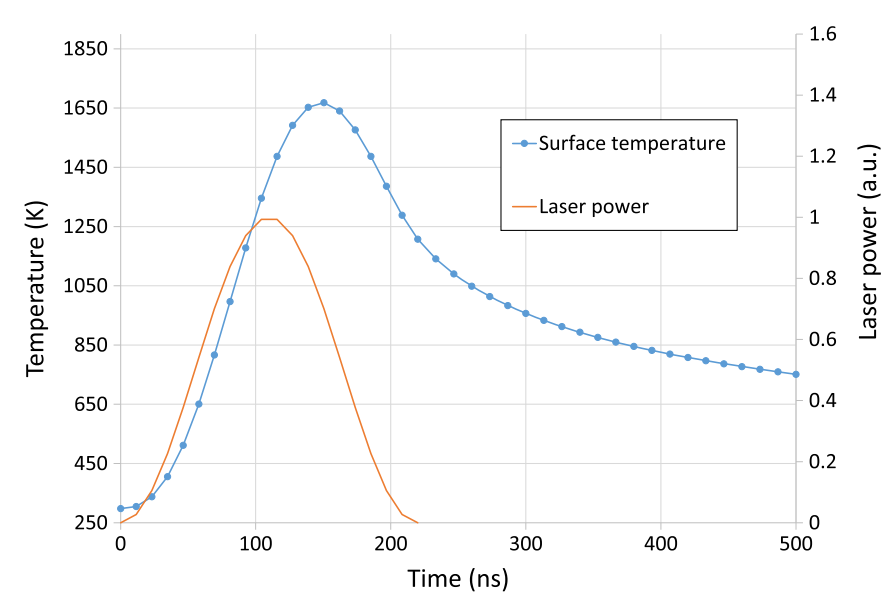

Fig. 8. Temperature evolution at the surface on the laser beam axis during a single laser pulse of $110 \mathrm{~ns}$ for a fluence of $1 \mathrm{~J} / \mathrm{cm}^{2}$ on a blank AISI 304L substrate.

Table 1. Oxide thickness after laser treatment $\left(237 \mathrm{~J} / \mathrm{cm}^{2}\right.$ total delivered) and a furnace oxidation $(100 \mathrm{~h}, 873 \mathrm{~K})$ with different contamination concentration in Eu.

\begin{tabular}{ll}
\hline $\begin{array}{l}\text { Surface contamination of } \mathrm{Eu} \\
\text { before oxidation } \\
\text { treatment }\left(\text { atoms } / \mathrm{cm}^{2}\right)\end{array}$ & Oxide thickness $(\mu \mathrm{m})$ \\
\hline 0 & $4.7 \pm 0.5$ \\
$1.6 \times 10^{19}$ & $1.6 \pm 0.2$ \\
$2.8 \times 10^{19}$ & $0.30 \pm 0.01$ \\
\hline
\end{tabular}

diffusivity of 304L stainless steel [12]. This fluence represents the minimum amount absorbed by the surface that leads to its melting. In our study, $\Phi_{\mathrm{m}}=0.36 \mathrm{~J} / \mathrm{cm}^{2}$. The absorptivity of the surface was $A=0.35$ and the melt threshold fluence could thus be estimated to $1 \mathrm{~J} / \mathrm{cm}^{2}$ which was lower than the laser fluences used for the laser oxidation. SEM observations (Fig. 7) of single impacts of a laser pulse under the pre oxidation conditions showed proof of fusion of the surface during the treatment.

A laboratory-developed analytical model [13] was used to simulate the laser heating of a metallic surface by nanosecond pulse radiation. The temperature spatial distribution or evolution in time could be determined. The simulation of a single impact of a $1064 \mathrm{~nm}$-pulse (with a duration of $110 \mathrm{~ns}$ at a frequency of $20 \mathrm{kHz}$ on a $304 \mathrm{~L}$ stainless steel substrate) was performed for different laser fluences. At low fluence $\left(1 \mathrm{~J} / \mathrm{cm}^{2}\right)$, it was seen that the temperature at the surface rose to its maximum of $1650 \mathrm{~K}$ after $150 \mathrm{~ns}$ and after $500 \mathrm{~ns}$, the metal temperature was $750 \mathrm{~K}$ (Fig. 8). We can assume that the increase of the laser pulse energy can lead to the melting temperature $(\theta=1678 \mathrm{~K})$. The simulation condition $\left(F=1 \mathrm{~J} / \mathrm{cm}^{2}\right)$ is coherent with the melt threshold calculated in equation (3). When the maximum temperature is reached, the temperature profile in depth shows that the thermally affected zone is sub micrometric, like the resulting oxide layers.

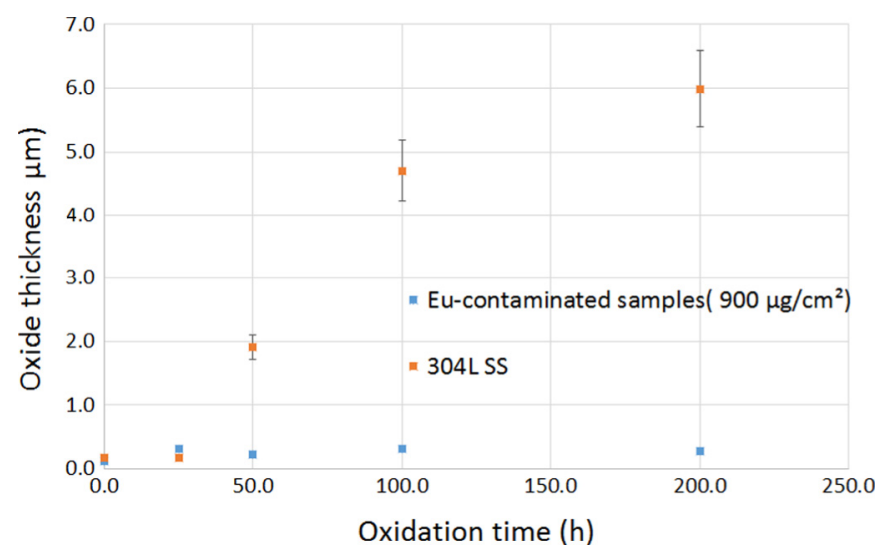

Fig. 9. Oxide thicknesses for different oxidation durations of Eucontaminated samples (blue) and blank samples (orange).

The surface temperature calculated $50 \mu \mathrm{s}$ (pulse repetition time) after a laser shot of $F=1 \mathrm{~J} / \mathrm{cm}^{2}$ is still at $330 \mathrm{~K}$. Thus, the pulse energy accumulation at the surface metal has a weak influence on the final surface temperature after one single pulse. Nevertheless, the simulation of multi impacts is needed to determine this influence during the laser treatment. Moreover, during laser scanning, the step between two pulses is less than $10 \%$ of the beam dimension. Thus we can consider that the treatment is performed on a surface which was already disturbed by the previous pulse. We will have to take into account the oxidation by the multi pulses on a substrate of 304L stainless steel with an oxide layer. For this purpose, a model of laser heating of an oxide layer on metallic surface has been developed in our laboratory and will be used [13]. More simulations need to be carried out but we can suppose that the oxidation is made from a liquid layer. This state allowed Eu to penetrate into the metal bulk and led to a fixed contamination of the sample surfaces.

The influence of the treatment duration on the oxide layer characteristics was studied. Contaminated samples $\left(2.8 \times 10^{19}\right.$ atoms $/ \mathrm{cm}^{2}$ of $\left.\mathrm{Eu}\right)$ were first preliminary treated by laser (14 W, 90\% overlap) and oxidized in a furnace at $873 \mathrm{~K}$ for duration from 25 to $200 \mathrm{~h}$. The same experiments were performed with 304L samples without contamination. The preliminary oxide layer obtained by laser was 100 $150 \mathrm{~nm}$ thick. The Figure 9 shows two main phenomena. On one hand, the contamination of $\mathrm{Eu}$ prevents the oxidation as expected in the literature [7-9]. On the other hand for blank samples, the oxide grows following a parabolic kinetics [7]. For the parabolic part of the curve, the parabolic rate is $k=6.14 \pm 0.75 \times 10^{5} \mu \mathrm{m}^{2} / \mathrm{s}$. Unlike the laser treatment, the oxidation by furnace is influenced by Eu-contamination. Indeed the experiments presented Table 1 shows that the increase Eu- concentration implies the limitation of the thickness of the oxide.

Even with the behavior of oxidation inhibitor of $\mathrm{Eu}$, our oxidation procedure allowed us to continue the oxidation process. Given the influence of the main parameters (delivered laser energy, furnace oxidation duration or $\mathrm{Eu}$ concentration), the thickness of the resulting oxide layer could be controlled and adjusted depending on the study. 


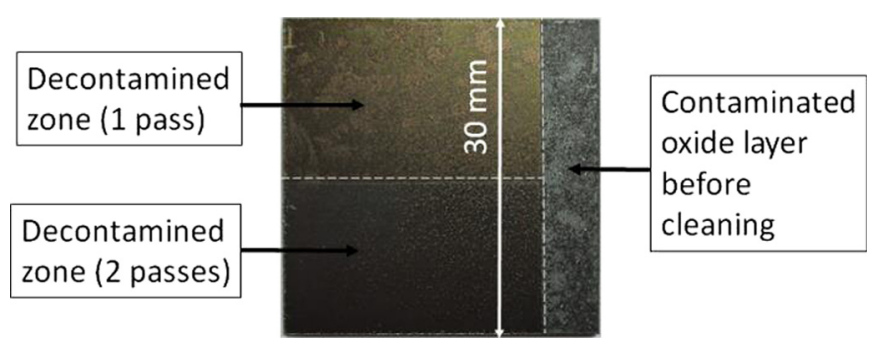

Fig. 10. Overview of oxidized 304L SS samples with an initial layer thickness of $3 \mu \mathrm{m}$ before and after laser cleaning $\left(5.9 \mathrm{~J} / \mathrm{cm}^{2} \cdot\right.$ per pulse and $80 \%$ of overlapping).

\section{Laser decontamination of oxidized metal surfaces}

According to the literature, the decontamination of metallic surfaces by excimers [4] and ytterbium fiber laser [3,5,14] was successful and demonstrated a decontamination percentage of up to $99 \%$ for thick oxide layer on stainless steel. The oxide layer was removed efficiently for the first passes but in a second phase, the decontamination stagnated. It was assumed that this limitation of the laser cleaning was the result of two phenomena: on the one hand, the trapping of the oxide and contaminants into micro-cracks of the materials preventing the laser beam from accessing the complete decontamination, and on the other hand, the heating of the surface during the laser treatment leading to the penetration of the contaminants in the metal bulk.

For decontamination of the oxide layer the laser setup was the same as the pre-oxidation one. But the fluence applied to ablate the oxide layer was in the range of $4-8 \mathrm{~J} / \mathrm{cm}^{2}$ with a spot overlapping of $80 \%$. As shown in Figure 10, the visual appearance of the sample before and after decontamination is different. After cleaning treatment, the metallic aspect of the sample is restored. The samples were analyzed by GD-OES in order to determine the thickness of the oxide layer, but since the remaining Euconcentration after cleaning was close to the detection limit of GD-OES, the GD-MS method was used (Fig. 11).

Figure 11 presents the GD-MS profiles for an oxide layer obtained after preliminary laser treatment $(9 \mathrm{~W}$, overlapping of $95 \%, E=608 \mathrm{~J} / \mathrm{cm}^{2}$ ) and furnace oxidation $(50 \mathrm{~h}, 873 \mathrm{~K})$ without and with decontamination treatment. The oxide layer was $3 \mu \mathrm{m}$-thick and had an Eucontamination of 0.1 wt.\% (Fig. 11a). It was seen that after 1 pass at $18 \mathrm{~W}$ and $80 \%$ overlapping, the resulting Eu-concentration was less than 0.02 wt.\% (Fig. 11b). After the decontamination treatment, the sample also had an oxide layer of $300 \mathrm{~nm}$ (Fig. 11b) which was believed to be the result of an incomplete ablation of the previous oxide layer or of additional oxidation during the laser cleaning.

In future, cleaning tests will be carried out to compare our results with the literature and to find optimal laser parameters to more efficient decontamination, such as energy per pulse, pulse duration and wavelength or spatial overlap.
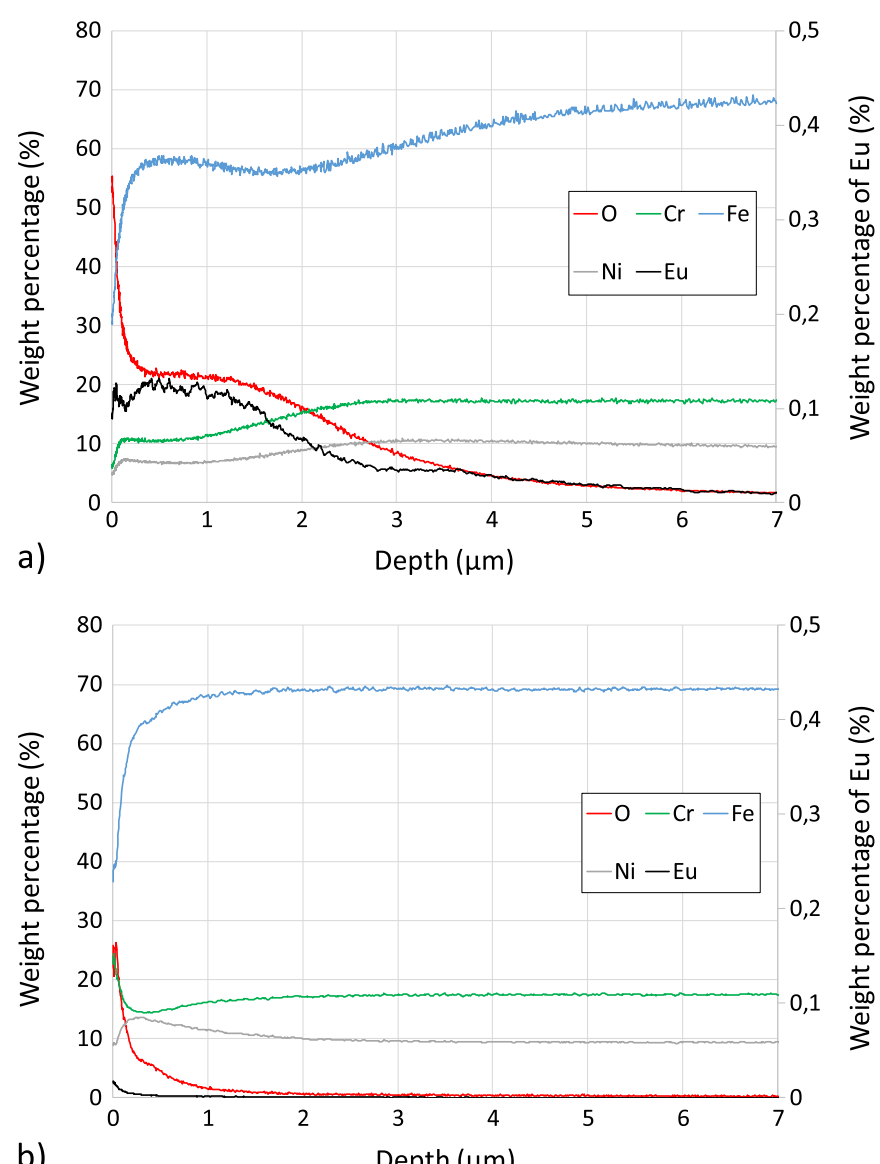

b)

Depth $(\mu \mathrm{m})$

Fig. 11. GD-MS profiles of a $3 \mu \mathrm{m}$ thick Eu-contaminated oxide layer on 304L SS (a) before decontamination; (b) after decontamination $\left(18 \mathrm{~W}\right.$, overlapping of $80 \%, F=7.6 \mathrm{~J} / \mathrm{cm}^{2} \cdot$ per pulse, 1 pass).

\section{Conclusion}

Our goal was to develop an oxidation process in order to prepare samples with characteristics similar to those of metal samples oxidized under real nuclear conditions. The creation of a contaminated oxide layer with controlled characteristics is a first step for the study of laser cleaning of metallic surface with micrometric cracks.

The oxidized sample of 304L SS was used to carry out studies with non-radioactive contaminants $(\mathrm{Eu})$ and conventional equipment. These oxides layers were prepared with a contamination by Eu solution spraying, preoxidation by laser and a final furnace treatment to continue the oxidation. The thicknesses of the obtained oxides ranged from $0.2 \mu \mathrm{m}$ up to $4.5 \mu \mathrm{m}$ with a mean Euconcentration of $6 \times 10^{16}$ atoms $/ \mathrm{cm}^{2}\left(15 \mu \mathrm{g} / \mathrm{cm}^{2}\right)$ in the bulk of oxide layer. The method using a furnace treatment simulated the oxidation of stainless steel when it is exposed to high temperature. The resulting oxide layer thickness could be controlled by the set of main parameters (delivered laser energy, duration of the oxidation by furnace or Eu concentration). 
It has been shown that laser heating with the parameters of the pre-oxidation led to the formation of a liquid layer of metal in which the Eu contamination could penetrate. The melting of a sub micrometric layer was then needed to fix the contamination the bulk of the layer.

The laser cleaning of the prepared samples resulted in a satisfactory decontamination rate and low residual contamination $(\leq 0.02$ wt.\%). Future cleaning tests will be carried out to determine laser parameters for more efficient decontamination, such as energy per pulse, pulse duration and wavelength or spatial overlap.

\section{References}

1. F. Brygo, Ch. Dutouquet, D. Le Guern, R. Oltra, A. Semerok, J.M. Weurlesse, Appl. Surf. Sci. 252, 2131 (2006)

2. F. Champonnois, F. Beaumont, C. Lascoutouna, US Patent 20110315666 A1, 2009

3. A. Leontyev, Ph.D. thesis, Université Paris Sud - Paris XI, 2011

4. Ph. Delaporte, M. Gastaud, W. Marine, M. Sentis, O. Uteza, P. Thouvenot, J.L. Alcatraz, J.M. Le Samedy, D. Blin, Appl. Surf. Sci. 197-198, 826 (2002)
5. A. Leontyev, A. Semerok, D. Farcage, P.Y. Thro, C. Grisolia, A. Widdowson, P. Coad, M. Rubel, Fusion Eng. Des. 86, 1728 (2011)

6. Z. Homonnay, E. Kuzmann, K. Varga, Z. Nemeth, A. Szabo, K. Rado, K.E. Mako, L. Köver, I. Cserny, D. Varga, J. Toth, J. Schunk, P. Tilky, G. Patek, J. Nucl. Mater. 348, 191 (2006)

7. F. Riffard, H. Buscail, E. Caudron, R. Cueff, C. Issartel, S. Perrier, Appl. Surf. Sci. 252, 3697 (2006)

8. N. Karimi, Ph.D. thesis, Université Blaise Pascal-ClermontFerrand II, 2007

9. N. Karimi, H. Buscail, F. Riffard, F. Rabasten R. Cueff, C. Issartel, E. Caudron, S. Perrier, Mater. Sci. Forum 595, 733 (2008)

10. M. Wautelet, Appl. Phys. A 50, 131 (1990)

11. D. Bäuerle, Chemical Processing with Lasers (Springer, Berlin, 2000)

12. P. Lacombe, G. Béranger, B. Baroux, Les aciers inoxydables (Les éditions de physique, 1990) (in French)

13. A. Semerok, S.V. Fomichev, J.-M. Weulersse, F. Brygo, P.-Y. Thro, C. Grisolia, J. Nucl. Mater. 420, 198 (2012)

14. V.P. Veiko, T. Y. Mutin, V.N. Smirnov, E.A. Shakhno, Laser Phys. 21, 608 (2011)

Cite this article as: Luisa Carvalho, Wilfried Pacquentin, Michel Tabarant, Hicham Maskrot, Alexandre Semerok, Growth of micrometric oxide layers to explore laser decontamination of metallic surfaces, EPJ Nuclear Sci. Technol. 3, 30 (2017) 